\title{
(6) OPEN ACCESS \\ Diagnostic accuracy of PAT-POPS and ManChEWS for admissions of children from the emergency department
}

\author{
Sarah Cotterill, ${ }^{1}$ Andrew G Rowland, ${ }^{2,3}$ Jacqueline Kelly, ${ }^{2}$ Helen Lees, ${ }^{2}$ \\ Mohammed Kamara ${ }^{2}$
}

${ }^{1}$ Centre for Biostatistics, University of Manchester, Manchester, UK

${ }^{2}$ Emergency Department, North Manchester General Hospital, Manchester, UK

${ }^{3}$ The University of Salford, Salford, UK

\section{Correspondence to} Dr Sarah Cotterill, Research Fellow, Centre for Biostatistics, Jean McFarlane Building, University of Manchester, Oxford Road, Manchester, M13 9PL, UK; sarah.cotterill@manchester. ac.uk

Received 12 January 2015 Revised 12 February 2016 Accepted 14 March 2016 Published Online First 11 April 2016

\section{CSLinked}

- http://dx.doi.org/10.1136/ emermed-2016-205877

\section{CrossMark}

To cite: Cotterill $S$,

Rowland AG, Kelly J, et al.

Emerg Med J 2016;33:756-

762

\section{ABSTRACT}

Background The Pennine Acute Trust (PAT) Paediatric Observation Priority Score (PAT-POPS) is a specific emergency department (ED) physiological and observational aggregate scoring system, with scores of 0-18. A higher score indicates greater likelihood of admission. The Manchester Children's Early Warning System (ManChEWS) assesses six physiological observations to create a trigger score, classified as Green, Amber or Red.

Methods Prospectively collected data were used to calculate PAT-POPS and ManChEWS on 2068 patients aged under 16 years (mean 5.6 years, SD 4.6) presenting over 1 month to a UK District General Hospital Paediatric ED. Receiver operating characteristics (ROC) comparison, using STATA V.13, was used to investigate the ability of ManChEWS and PAT-POPS to predict admission to hospital within $72 \mathrm{~h}$ of presentation to the ED.

Results Comparison of the area under the ROC curve indicates that the ManChEWS ROC is $0.67(95 \% \mathrm{Cl}$ 0.64 to 0.70$)$ and the PAT-POPS ROC is $0.72(95 \% \mathrm{Cl}$ 0.68 to 0.75 ). The difference is statistically significant. At a PAT-POPS cut-off of $\geq 2,80 \%$ of patients had their admission risk correctly classified (positive likelihood ratio $3.40,95 \% \mathrm{Cl} 2.90$ to 3.98 ) whereas for ManChEWS with a cut off of $\geq$ Amber only $71 \%$ of patients were correctly classified (positive likelihood ratio $2.18,95 \% \mathrm{Cl} 1.94$ to 2.45 ).

Conclusions PAT-POPS is a more accurate predictor of admission risk than ManChEWS. Replacing ManChEWS with PAT-POPS would appear to be clinically appropriate in a paediatric ED. This needs validation in a multicentre study.

\section{INTRODUCTION}

Health professionals make judgements on whether children attending emergency departments (EDs) require hospitalisation, or can safely be sent home. These judgements require a complex assessment of the child's health and an estimation of the potential for improvement or deterioration. Since at least 2006 it has been recommended that early identification systems to recognise children developing critical illness should be used. ${ }^{1}$ Many paediatric early warning scores (EWS) use track and trigger systems, relying on repeated observations over time, intended for use with hospitalised children, ${ }^{2-9}$ to predict which children are likely to deteriorate, rather than who requires admission from an ED. There is a need for a specific ED early warning

\section{Key messages}

What is already known on this subject?

- There is a need for a specific emergency department early warning system for children.

- Manchester Children's Early Warning System (ManChEWS) is one scoring system, which correctly identifies the deteriorating child, but can overtrigger which may lead staff to become immune to the score.

- Paediatric Observation Priority Score (POPS) is a new scoring system, combining physiological measurement and clinical observation.

What might this study add?

- A Pennine Acute Trust (PAT) Paediatric Observation Priority Score (PAT-POPS) score $\geq 2$ would correctly identify about $50 \%$ of children who need to be admitted from the ED, and a PAT-POPS score $<2$ would correctly identify $85 \%$ of cases who could be discharged from the ED.

- PAT-POPS has slightly higher diagnostic accuracy for predicting the likelihood of admission than an existing tool often used in this population, ManChEWS.

- PAT-POPS can be used for patients with either trauma or illness.

system, validated on ED patients. ${ }^{10}$ In the absence of an ED EWS, our ED used The Royal Manchester Children's Hospital Early Warning System (ManChEWS), a track and trigger system. ${ }^{11}$ Variation in six physiological parameters (RR, oxygen requirement, heart rate, systolic BP, capillary refill time and conscious level) is scored during routine nursing observations (figure 1). While ManChEWS correctly identifies the deteriorating child it overtriggers which may lead staff to become immune to the score. ${ }^{4}$

The Pennine Acute Trust (PAT) Paediatric Observation Priority Score (PAT-POPS) is a new EWS, designed for use in children's ED, combining physiological measurement and clinical observation into an aggregate scoring system (figure 2). The target user of PAT-POPS is nursing staff in the ED as part of their post-triage initial assessment. PAT-POPS has been adapted from the Paediatric Observational Priority Score (POPS), ${ }^{12} 13$ designed 
Figure 1 Manchester Children's Early Warning System (ManChEWS) scoring system.

Respiratory rate
\begin{tabular}{|l|c|c|c|c|c|}
\hline \multicolumn{1}{|c|}{ Age } & Red & Amber & Green & Amber & Red \\
\hline Under 4 months & Under 20 & $20-29$ & $30-39$ & $40-54$ & Over 54 \\
\hline 4 months -2 years & Under 15 & $15-24$ & $25-34$ & $35-55$ & Over 55 \\
\hline 2 to 5 years & Under 10 & $10-19$ & $20-29$ & $30-45$ & Over 45 \\
\hline 5 to 12 years & Under 10 & $10-19$ & $20-29$ & $30-45$ & Over 45 \\
\hline Over 12 years & Under 10 & $10-14$ & $15-24$ & $25-45$ & Over 45 \\
\hline
\end{tabular}

Oxygen requirement

\begin{tabular}{|l|l|l|l|}
\hline \multicolumn{1}{|c|}{ Age } & Green & Amber & Red \\
\hline Under 4 months & Over $97 \%$ in air & $\mathrm{O}_{2}$ to keep over $97 \%$ & Below $97 \%$ in $\mathrm{O}_{2}$ \\
\hline 4 months -2 years & Over $97 \%$ in air & $\mathrm{O}_{2}$ to keep over $97 \%$ & Below $97 \%$ in $\mathrm{O}_{2}$ \\
\hline 2 to 5 years & Over $97 \%$ in air & $\mathrm{O}_{2}$ to keep over $97 \%$ & Below $97 \%$ in $\mathrm{O}_{2}$ \\
\hline 5 to 12 years & Over $97 \%$ in air & $\mathrm{O}_{2}$ to keep over $97 \%$ & Below $97 \%$ in $\mathrm{O}_{2}$ \\
\hline Over 12 years & Over $97 \%$ in air & $\mathrm{O}_{2}$ to keep over $97 \%$ & Below $97 \%$ in $\mathrm{O}_{2}$ \\
\hline
\end{tabular}

Heart Rate

\begin{tabular}{|l|c|c|c|c|c|}
\hline \multicolumn{1}{|c|}{ Age } & Red & Amber & Green & Amber & Red \\
\hline Under 4 months & Below 80 & $80-109$ & $110-160$ & $160-199$ & Over 200 \\
\hline 4 months - 2 years & Below 80 & $80-99$ & $100-149$ & $150-190$ & Over 190 \\
\hline 2 to 5 years & Below 60 & $60-79$ & $80-119$ & $120-150$ & Over 150 \\
\hline 5 to 12 years & Below 60 & $60-69$ & $70-119$ & $120-150$ & Over 150 \\
\hline Over 12 years & Below 55 & $56-64$ & $65-99$ & $100-150$ & Over 150 \\
\hline
\end{tabular}

Systolic Blood pressure

\begin{tabular}{|l|c|c|c|c|c|}
\hline \multicolumn{1}{|c|}{ Age } & Red & Amber & Green & Amber & Red \\
\hline Under 4 months & Below 50 & $50-59$ & $60-80$ & $81-99$ & Over 100 \\
\hline 4 months -2 years & Below 60 & $60-69$ & $70-90$ & $90-110$ & Over 110 \\
\hline 2 to 5 years & Below 60 & $60-89$ & $90-129$ & $130-150$ & Over 150 \\
\hline 5 to 12 years & Below 80 & $60-89$ & $90-129$ & $130-150$ & Over 150 \\
\hline Over 12 years & Below 80 & $60-89$ & $90-129$ & $130-160$ & Over 160 \\
\hline
\end{tabular}

Capillary refill Time

\begin{tabular}{|l|l|l|l|}
\hline \multicolumn{1}{|c|}{ Age } & \multicolumn{1}{c|}{ Green } & Amber & Red \\
\hline Under 4 months & Under 2 seconds & $3-4$ seconds & Over 4 seconds \\
\hline 4 months -2 years & Under 2 seconds & $3-4$ seconds & Over 4 seconds \\
\hline 2 to 5 years & Under 2 seconds & $3-4$ seconds & Over 4 seconds \\
\hline 5 to 12 years & Under 2 seconds & $3-4$ seconds & Over 4 seconds \\
\hline Over 12 years & Under 2 seconds & $3-4$ seconds & Over 4 seconds \\
\hline
\end{tabular}

Conscious Level

\begin{tabular}{|l|l|l|l|}
\hline \multicolumn{1}{|c|}{ Age } & Green & Amber & Red \\
\hline Under 4 months & Alert & Responds to pain / voice & Unresponsive \\
\hline 4 months -2 years & Alert & Responds to pain / voice & Unresponsive \\
\hline 2 to 5 years & Alert & Responds to pain / voice & Unresponsive \\
\hline 5 to 12 years & Alert & Responds to pain / voice & Unresponsive \\
\hline Over 12 years & Alert & Responds to pain / voice & Unresponsive \\
\hline
\end{tabular}

by the Paediatric Emergency Medicine Leicester Academic Group.

The original POPS demonstrated utility as a patient safety system in an analysis of the admission length of 24000 patients who attended a UK ED. ${ }^{14}$ With an area under the curve (AUC) for the receiver operating characteristic (ROC) curve of 0.8 , it was concluded that POPS may assist in reducing unnecessary admissions and preventing episodes of missed or incorrect diagnoses.

Over a period of 1 month, we calculated PAT-POPS and ManChEWS scores for 2068 children attending our paediatric $\mathrm{ED}$, and recorded whether the child was admitted or discharged. We compared the diagnostic accuracy of the two scoring methods in estimating the likelihood of admission or discharge. The overall aim of this study was to compare the diagnostic accuracy of PAT-POPS and ManChEWS for estimating whether or not hospital admission is required among children presenting to an ED with trauma or medical diagnoses.

\section{METHOD}

\section{Participants}

The study population was children aged under 16 years attending the ED of North Manchester General Hospital (part of PAT) during March 2012. Children who left the ED before they could be assessed for admission, or where insufficient data were available to calculate PAT-POPS and ManChEWS, were excluded.

\section{Test methods}

The reference standard for our study was admission to hospital within $72 \mathrm{~h}$ of first presentation at the ED. This was a prospective study of a consecutive series of patients: data collection was planned before the index tests and reference standard were performed. The decision on whether or not to admit a child to inpatient care was made by the clinician seeing the patient, using their subjective clinical experience as well as departmental guidelines, including ManChEWS. The disposal outcome (discharged or admitted) for each attendance was recorded on the 


\begin{tabular}{|c|c|c|c|c|c|c|}
\hline Age & Score & 2 & 1 & $\mathbf{0}$ & $\mathbf{1}$ & 2 \\
\hline Any & Saturations & $\begin{array}{c}<90 \% \text { (or }>50 \% \text { oxygen } \\
\text { requirement) }\end{array}$ & $\begin{array}{c}90-94 \% \text { (or }>30 \% \\
\text { oxygen requirement) }\end{array}$ & $>94 \%$ & $\begin{array}{c}90-94 \% \text { (or }>30 \% \\
\text { oxygen requirement) }\end{array}$ & $\begin{array}{c}<90 \% \text { (or }>50 \% \text { oxygen } \\
\text { requirement) }\end{array}$ \\
\hline Any & Breathing & Stridor & $\begin{array}{c}\text { Audible grunt or tracheal } \\
\text { tug or wheeze }\end{array}$ & No distress & $\begin{array}{l}\text { Mild or Moderate } \\
\text { Recession }\end{array}$ & Severe Recession \\
\hline Any & AVPU & Pain & Voice & Alert & Voice & Pain \\
\hline Any & $\begin{array}{c}\text { Nurse's } \\
\text { judgement }\end{array}$ & Child looks unwell & Minimal concern & $\begin{array}{l}\text { No concern and } \\
\text { child looks well }\end{array}$ & Minimal concern & Child looks unwell \\
\hline Any & Behaviour & Floppy & Listless & Normal for age & Inappropriate & Agitated \\
\hline Any & $\begin{array}{c}\text { Specific } \\
\text { Conditions }\end{array}$ & Oncology Patient & $\begin{array}{l}\text { Patient on long term } \\
\text { steroids or diabetic or has } \\
\text { open access letter }\end{array}$ & $\mathrm{X}$ & $\begin{array}{l}\text { Ex-premature or any } \\
\text { syndromic condition or } \\
\text { known metabolic } \\
\text { disorder }\end{array}$ & $\begin{array}{l}\text { Congenital Heart Disease } \\
\text { or known asthmatic with } \\
\text { previous PICU admission }\end{array}$ \\
\hline \multirow{3}{*}{$<4$ months } & Pulse & $<90$ & $90-109$ & $110-160$ & 161-199 & $>200$ \\
\hline & $\mathbf{R R}$ & $<30$ & $30-35$ & $36-45$ & $46-50$ & $>50$ \\
\hline & Temp & $<35^{\circ} \mathrm{C}$ & $35-35.9^{0} \mathrm{C}$ & $36-37.5^{0} \mathrm{C}$ & $37.6-39^{\circ} \mathrm{C}$ & $>39^{\circ} \mathrm{C}$ \\
\hline \multirow{3}{*}{ 4-12 months } & Pulse & $<90$ & $90-109$ & $110-160$ & $161-180$ & $>180$ \\
\hline & $\mathbf{R R}$ & $<25$ & $25-29$ & $30-40$ & $41-50$ & $>50$ \\
\hline & Temp & $<35^{\circ} \mathrm{C}$ & $35-35.9^{\circ} \mathrm{C}$ & $36-37.5^{\circ} \mathrm{C}$ & $37.6-39^{\circ} \mathrm{C}$ & $>39^{\circ} \mathrm{C}$ \\
\hline \multirow{3}{*}{$1-2$ years } & Pulse & $<90$ & $90-99$ & $100-150$ & $151-170$ & $>170$ \\
\hline & $\mathbf{R R}$ & $<20$ & $20-24$ & $25-35$ & $36-50$ & $>50$ \\
\hline & Temp & $<35^{\circ} \mathrm{C}$ & $35-35.9^{\circ} \mathrm{C}$ & $36-38.4^{0} \mathrm{C}$ & $38.5-40^{\circ} \mathrm{C}$ & $>40^{\circ} \mathrm{C}$ \\
\hline \multirow{3}{*}{$2-5$ years } & Pulse & $<80$ & $80-94$ & $95-140$ & $141-160$ & $>160$ \\
\hline & $\mathbf{R R}$ & $<20$ & $20-24$ & $25-30$ & $31-40$ & $>40$ \\
\hline & Temp & $<35^{\circ} \mathrm{C}$ & $35-35.9^{0} \mathrm{C}$ & $36-38.4^{0} \mathrm{C}$ & $38.5-40^{\circ} \mathrm{C}$ & $>40^{\circ} \mathrm{C}$ \\
\hline \multirow{3}{*}{ 5-12 years } & Pulse & $<70$ & $70-79$ & $80-120$ & $121-150$ & $>150$ \\
\hline & $\mathbf{R R}$ & $<15$ & 15-19 & $20-25$ & $26-40$ & $>40$ \\
\hline & Temp & $<35^{\circ} \mathrm{C}$ & $35-35.9^{\circ} \mathrm{C}$ & $36-38.4^{0} \mathrm{C}$ & $38.5-40^{\circ} \mathrm{C}$ & $>40^{\circ} \mathrm{C}$ \\
\hline \multirow{3}{*}{$>12$ years } & Pulse & $<60$ & $60-64$ & $65-100$ & $101-150$ & $>150$ \\
\hline & $\mathbf{R R}$ & $<10$ & $10-14$ & $15-25$ & $26-40$ & $>40$ \\
\hline & Temp & $<35^{\circ} \mathrm{C}$ & $35-35.9^{\circ} \mathrm{C}$ & $36-38.4^{0} \mathrm{C}$ & $38.5-40^{\circ} \mathrm{C}$ & $>40^{\circ} \mathrm{C}$ \\
\hline
\end{tabular}

Figure 2 North Manchester modified Pennine Acute Trust (PAT) Paediatric Observation Priority Score (PAT-POPS) chart.

electronic patient record. Information was collected on re-presentations, and where a child re-presented to the ED with the same clinical problem within $72 \mathrm{~h}$ and was admitted, we counted that as an admission for the original presentation. Data on admission were recorded by hospital staff in the hospital electronic record, and then extracted by the research team retrospectively.

ManChEWS is scored Green, Amber or Red. ${ }^{11}$ The score encourages observation monitoring and empowers nursing staff by providing clear instructions of what actions should be taken dependent on the status of the child. All observations must be within the normal range for the age of the child for the award of Green status. Any physiological parameters that are abnormal, but within the defined range, lead to Amber status. Any parameters that are very abnormal and which lie outside of the Green or Amber ranges result in a Red status, indicating that the child has potentially significant physiological disturbance.

PAT-POPS is assessed as a score between 0 (likely low risk of serious illness) and 18 (likely high risk of serious illness) and is a checklist which quickly scores acutely ill children on age-related physiological measures (heart rate, RR, temperature) and behavioural and risk-identifiers (such as oxygen saturations, breathing pattern, conscious level, nurse's judgement of how well the child is, child's behaviour) using easy to collect data (figure 2). Measurements of the physiological variables and subjective assessments necessary to calculate ManChEWS and PAT-POPS for each patient were taken by nursing staff in the ED either at the point of triage or during the child's assessment in the ED.

Before the study, nursing staff were trained in the use of PAT-POPS. Nursing staff were already familiar with ManChEWS. Patient data for the PAT-POPS and ManChEWS assessment were collected prior to the admission decision, so there was blinding to the outcome. The persons who transcribed the data from the electronic patient record to the PAT-POPS data sheet did so retrospectively, some time after admission, and so were not blinded to the outcome. The doctor making the admission decision was not blinded to the ManChEWS score and may have used it in their decision-making. Doctors were blinded to the PAT-POPS scores, which were recorded onto data capture sheets rather than directly into the patient's notes. The doctors received no training on PAT-POPS to minimise the chances of them using it as part of a decision-making process if they happened to see the data capture sheet.

\section{Statistical methods}

We report the age, gender and diagnosis of our sample of patients, using descriptive statistics. We have calculated the sensitivity and specificity of PAT-POPS and ManChEWS to predict admission and we present this data as comparative ROC curves. We report the positive and negative likelihood ratios at different cut points of PAT-POPS and ManChEWS. ${ }^{15}$ We present 95\% CIs and $\mathrm{p}$ values, as appropriate. We have compared the sensitivity and specificity of PAT-POPS to predict admission for separate groups of children with illness or trauma, using ROC analysis, and followed the DeLong method to compare the AUC of ROC curves for PAT-POPS and ManChEWS. ${ }^{16}$ The data were entered into Microsoft Excel and analysed using STATA V.13 (StataCorp. 2013. Stata Statistical Software: Release 13. College Station, TX: StataCorp LP).

\section{Ethics}

This service evaluation was approved by the hospital's audit department and no formal ethical approval was required as no clinical decisions were made on the basis of the PAT-POPS data and we continued to manage each patient in accordance with our ED guidelines. 
Figure 3 Study flow diagram.

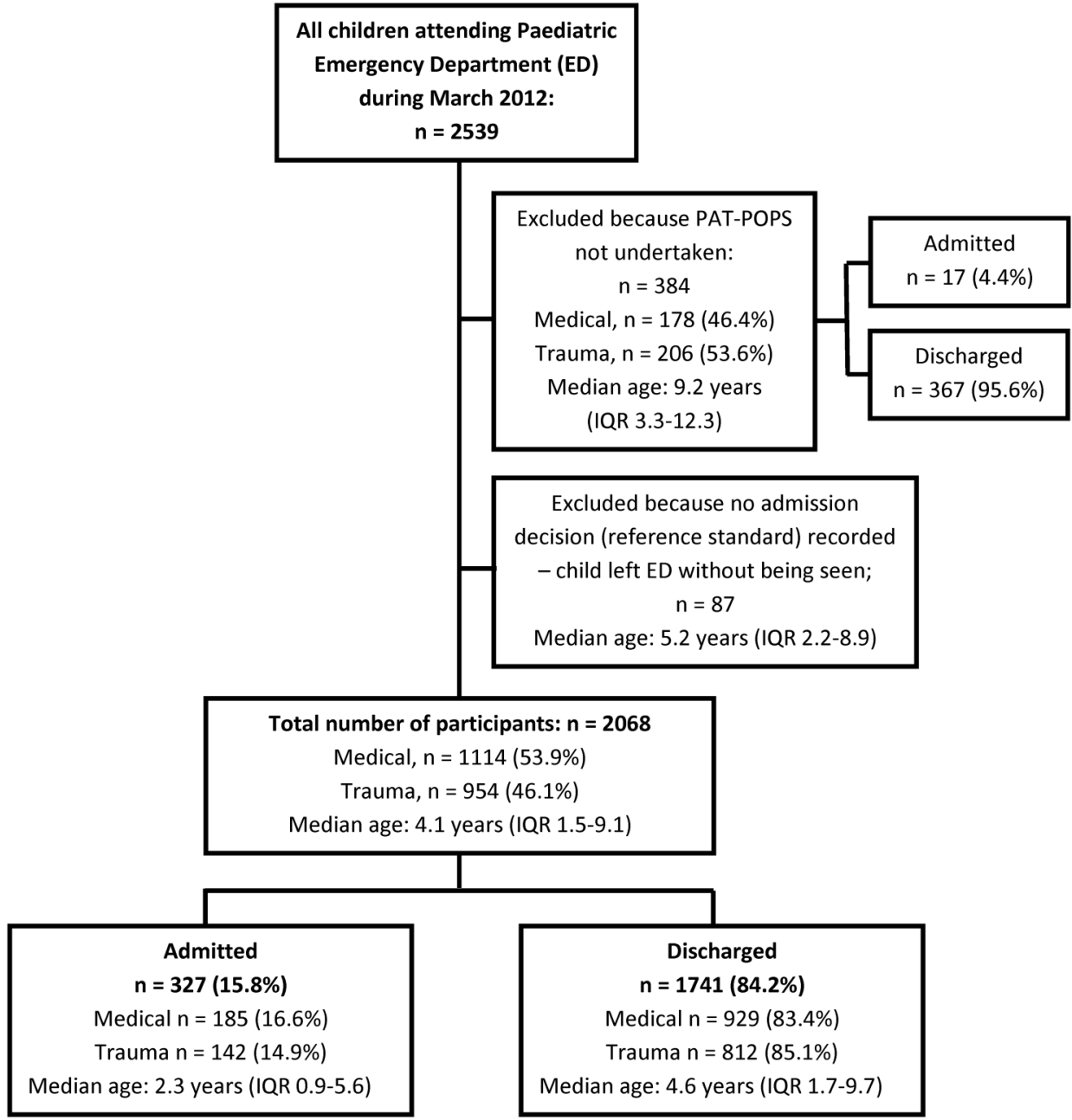

\section{RESULTS}

\section{Participants}

Between 1 March 2012 and 31 March 2012, 2539 children attended the paediatric ED. We have omitted 87 children with no reference standard who left the ED without being seen, and 384 children with no PAT-POPS recorded. There are two likely reasons for not recording PAT-POPS. First, where there was no wait in the ED a disposal outcome decision may have been made before nursing assessment. Second, PAT-POPS was a new tool and some staff may have forgotten to calculate a PAT-POPS for each patient. The analysis is based on the remaining 2068 patients (figure 3). Among the 2068 children, the mean age was 5.6 years, median 4.1 years (range 1 day to 15 years), 954 $(46 \%)$ presented with a trauma and $1114(54 \%)$ with a medical condition. ${ }^{17} \mathrm{~A}$ comparison of children with and without a PAT-POPS recorded score indicates that the children who were assessed using PAT-POPS were, on average, younger (5.6 years compared with 8.2 years), and were less likely to attend with trauma (46.1\% compared with 53.6\%), more likely to re-attend within $72 \mathrm{~h}(3.7 \%$ compared with $1.6 \%)$ and more likely to be admitted (15.8\% compared with 4.4\%). All these differences are statistically significant $(p<0.05)$, using Mann-Whitney or proportion tests, as appropriate. It appears that the 384 children who were not assessed for PAT-POPS were less ill than those who were assessed.

\section{Hospital admission}

Of the 2068 children, 317 (15.3\%) were admitted to hospital at first attendance. Seventy-six children (3.7\%) re-attended the ED with the same complaint one or more times within $72 \mathrm{~h}$ of first attendance and 15 (19.7\%) of these were admitted (3 of whom had also been admitted on first attendance, and then discharged). In total, $327(15.81 \%)$ were admitted to hospital within $72 \mathrm{~h}$ of first attendance.

\section{Test results}

Measurement of the variables necessary to calculate ManChEWS and PAT-POPS was undertaken as soon as possible after arrival to the ED. Over $95 \%$ of patients were seen and either admitted or discharged within a period of $4 \mathrm{~h}$ from the time of arrival.

\section{ManChEWS results}

Across the 2068 patients, 1397 (67.55\%) were Green, 573 (27.71\%) Amber and 98 (4.74\%) Red (table 1).

\section{PAT-POPS results}

The mean PAT-POPS score across all 2068 patients was 0.9 (SD 1.58). The median was 0 . Overall $62 \%$ of patients scored a PAT-POPS of 0 . No patient had a PAT-POPS score of greater than 12 (table 1 ).

No adverse events were reported from performing any of the index tests or reference standard. There were no deaths of children in the ED during the study period.

Diagnostic accuracy of ManChEWS and PAT-POPS

Sensitivity and specificity

Sensitivity and specificity of ManChEWS to predict admission were calculated at each ManChEWS value (table 2). A Red 
Table 1 A cross tabulation of Manchester Children's Early Warning System (ManChEWS) and Paediatric Observation Priority Score (POPS) scores by admission

\begin{tabular}{|c|c|c|c|}
\hline & Admitted & Discharged & Total \\
\hline \multicolumn{4}{|l|}{ ManChEWS score } \\
\hline \multirow[t]{2}{*}{ Green } & 132 & 1265 & 1397 \\
\hline & $9.45 \%$ & $90.55 \%$ & $100 \%$ \\
\hline \multirow[t]{2}{*}{ Amber } & 144 & 429 & 573 \\
\hline & $25.13 \%$ & $74.87 \%$ & $100 \%$ \\
\hline \multirow[t]{2}{*}{ Red } & 51 & 47 & 98 \\
\hline & $52.04 \%$ & $47.96 \%$ & $100 \%$ \\
\hline \multicolumn{4}{|l|}{ PAT-POPS score } \\
\hline \multirow[t]{2}{*}{0} & 108 & 1164 & 1272 \\
\hline & $33.0 \%$ & $66.9 \%$ & $61.5 \%$ \\
\hline \multirow[t]{2}{*}{1} & 57 & 323 & 380 \\
\hline & $17.4 \%$ & $18.6 \%$ & $18.4 \%$ \\
\hline \multirow[t]{2}{*}{2} & 44 & 137 & 181 \\
\hline & $13.5 \%$ & $7.9 \%$ & $8.8 \%$ \\
\hline \multirow[t]{2}{*}{3} & 42 & 56 & 98 \\
\hline & $12.8 \%$ & $3.2 \%$ & $4.7 \%$ \\
\hline \multirow[t]{2}{*}{4} & 18 & 32 & 50 \\
\hline & $5.5 \%$ & $1.8 \%$ & $2.4 \%$ \\
\hline \multirow[t]{2}{*}{5} & 18 & 20 & 38 \\
\hline & $5.5 \%$ & $1.2 \%$ & $1.8 \%$ \\
\hline \multirow[t]{2}{*}{6} & 10 & 6 & 16 \\
\hline & $3.1 \%$ & $0.3 \%$ & $0.8 \%$ \\
\hline \multirow[t]{2}{*}{7} & 10 & 0 & 10 \\
\hline & $3.1 \%$ & $0.0 \%$ & $0.5 \%$ \\
\hline \multirow[t]{2}{*}{8} & 9 & 3 & 12 \\
\hline & $2.8 \%$ & $0.2 \%$ & $0.6 \%$ \\
\hline \multirow[t]{2}{*}{9} & 4 & 0 & 4 \\
\hline & $1.2 \%$ & $0.0 \%$ & $0.2 \%$ \\
\hline \multirow[t]{2}{*}{10} & 3 & 0 & 3 \\
\hline & $0.9 \%$ & $0.0 \%$ & $0.2 \%$ \\
\hline \multirow[t]{2}{*}{11} & 1 & 0 & 1 \\
\hline & $0.3 \%$ & $0.0 \%$ & $0.1 \%$ \\
\hline \multirow[t]{2}{*}{12} & 3 & 0 & 3 \\
\hline & $0.9 \%$ & $0.0 \%$ & $0.2 \%$ \\
\hline Mean PAT-POPS & 2.3 & 0.6 & 0.9 \\
\hline SD & 2.62 & 1.11 & 1.58 \\
\hline Total, N & 327 & 1741 & 2068 \\
\hline
\end{tabular}

ManChEWS score identifies around 16\% of those who were admitted, and successfully identifies almost all of those who were not admitted. An Amber or Red score identifies almost $60 \%$ of those who were admitted, and $73 \%$ of those who were discharged from the ED. Looking at the positive likelihood ratios, children with a ManChEWS score of Amber or Red are twice as likely to be admitted as children assessed as Green. Children with a ManChEWS score of Red are almost six times as likely to be admitted, compared with children assessed as Green or Amber.

Sensitivity and specificity of PAT-POPS to predict admission were calculated at each PAT-POPS value (table 2). A PAT-POPS score of 9 or above correctly identifies all of those who were sent home, but has poor sensitivity. Sensitivity improves as the cut point lowers, without great loss of specificity until under 2. A PAT-POPS score of 2 or more successfully identifies $50 \%$ of those who were admitted, and $85 \%$ of those who were sent home. Looking at the positive likelihood ratios, children with a PAT-POPS cut point of 2 or more are more than three times as likely to be admitted as children with 0 or 1 .

\section{Receiver operating characteristics}

Sensitivity was plotted against (1-specificity) for each possible cut-off of ManChEWS and PAT-POPS in ROC curves (figure 4). The area under the ROC curve for ManChEWS is $0.67(95 \%$ CI 0.64 to 0.70$)$ and for PAT-POPS is 0.72 (95\% CI 0.68 to 0.75 ). The difference is statistically significant $(\mathrm{p}<0.01)$.

\section{Use of PAT-POPS for trauma and medical patients}

Sensitivity was plotted against (1-specificity) to draw separate ROC curves for the use of PAT-POPS among medical and trauma patients (figure not shown). The area under the ROC curve is 0.73 for medical patients and 0.69 for trauma patients. This analysis suggests that the usefulness of PAT-POPS to predict admission is similar among both trauma and medical patients, although slightly higher in medical patients. The pattern is repeated for ManChEWS: in medical patients, the area under the ROC curve is 0.69 , and in trauma patients it is 0.66 .

\section{LIMITATIONS}

This is a single-centre study and the results could have been different in another centre with an alternative arrangement of services and a different admission threshold. The outcome measure used in the study is whether the child was admitted to hospital, as assessed by an ED clinician. We endeavoured to increase the robustness of that measure by including any readmissions within $72 \mathrm{~h}$. Future studies could consider level of inpatient care, admissions to other hospitals and length of stay.

Decision-making on a heterogeneous population of medical and trauma patients differs widely. There are some conditions which automatically trigger an admission regardless of the PAT-POPS (such as deliberate self-harm, child protection cases or a child with a fracture requiring operative management).

This study was based on patients who attended the ED during 1 month (March) and diagnoses in paediatrics do have a seasonal variation, with higher rates of respiratory conditions in winter and minor trauma in summer. March was chosen because this month coincided with some dedicated time made available in work schedules for members of the study team. In future studies sampling patients from throughout the year will be important.

Some patients who attended the ED during the month of the study did not have PAT-POPS recorded, because of an absence of some of the data used to calculate the score. The missing data could not be calculated retrospectively because PAT-POPS includes subjective nurse assessments of the child's behaviour and condition, which is not routinely collected.

Although our results show that PAT-POPS appears slightly better than ManChEWS at predicting admission of children from the ED, PAT-POPS scores are disadvantaged by nurses being less familiar with the PAT-POPS tool and hence more likely to make errors in scoring and clinicians not being blinded against the ManChEWS score.

Nonetheless, it is important to acknowledge that the differences between those two scoring systems may not be clinically significant. 
Table 2 Sensitivity and specificity of Manchester Children's Early Warning System (ManChEWS) and Paediatric Observation Priority Score (POPS) to predict admission to the emergency department (ED)

\begin{tabular}{|c|c|c|c|c|}
\hline Cut point for admission decision & Sensitivity & Specificity & Likelihood ratio+ & Likelihood ratio- \\
\hline \multicolumn{5}{|l|}{ ManChEWS } \\
\hline Admit all (Green, Amber, Red) & $100.00 \%$ & $0.00 \%$ & 1.00 & \\
\hline \multirow[t]{2}{*}{ Admit if Amber or Red } & $59.63 \%$ & $72.66 \%$ & 2.18 & 0.56 \\
\hline & (54.08 to 64.96 ) & (70.49 to 74.73 ) & (1.94 to 2.45$)$ & (0.49 to 0.64$)$ \\
\hline \multirow[t]{2}{*}{ Admit if Red } & $15.60 \%$ & $97.30 \%$ & 5.78 & 0.87 \\
\hline & (11.93 to 20.09 ) & (0.96 to 0.98$)$ & (3.96 to 8.43 ) & (0.83 to 0.91$)$ \\
\hline Admit none & $0.00 \%$ & $100.00 \%$ & & 1.00 \\
\hline \multicolumn{5}{|l|}{ POPS } \\
\hline$(\geq 0)$ & $100.00 \%$ & $0.00 \%$ & 1.00 & \\
\hline \multirow[t]{2}{*}{$(\geq 1)$} & $66.97 \%$ & $66.86 \%$ & 2.02 & 0.49 \\
\hline & (61.55 to 71.99 ) & (64.58 to 69.06$)$ & (1.83 to 2.24$)$ & (0.42 to 0.58$)$ \\
\hline \multirow[t]{2}{*}{$(\geq 2)$} & $49.54 \%$ & $85.41 \%$ & 3.40 & 0.59 \\
\hline & (44.01 to 55.09 ) & (83.65 to 87.02 ) & (2.90 to 3.98$)$ & (0.53 to 0.66$)$ \\
\hline \multirow[t]{2}{*}{$(\geq 3)$} & $36.09 \%$ & $93.28 \%$ & 5.37 & 0.69 \\
\hline & (30.92 to 41.58 ) & (91.98 to 94.39 ) & (4.28 to 6.74$)$ & (0.63 to 0.74$)$ \\
\hline \multirow[t]{2}{*}{$(\geq 4)$} & $23.24 \%$ & $96.50 \%$ & 6.63 & 0.80 \\
\hline & (18.85 to 28.28 ) & (95.49 to 97.29 ) & (4.84 to 9.09 ) & (0.75 to 0.84 ) \\
\hline \multirow[t]{2}{*}{$(\geq 5)$} & $17.74 \%$ & $98.33 \%$ & 10.65 & 0.84 \\
\hline & (13.84 to 22.41 ) & (97.58 to 98.86 ) & (6.93 to 16.37 ) & (0.80 to 0.88 ) \\
\hline \multirow[t]{2}{*}{$(\geq 6)$} & $12.23 \%$ & $99.48 \%$ & 23.66 & 0.88 \\
\hline & (8.98 to 16.40 ) & (98.98 to 99.75 ) & (11.59 to 48.29 ) & (0.85 to 0.92$)$ \\
\hline \multirow[t]{2}{*}{$(\geq 7)$} & $9.17 \%$ & $99.83 \%$ & 53.24 & 0.91 \\
\hline & (6.37 to 12.97 ) & (99.45 to 99.96 ) & $\mathrm{n} / \mathrm{a}$ & (0.88 to 0.94 ) \\
\hline \multirow[t]{2}{*}{$(\geq 8)$} & $6.12 \%$ & $99.83 \%$ & 35.49 & 0.94 \\
\hline & (3.87 to 9.44 ) & (99.45 to 99.96 ) & $\mathrm{n} / \mathrm{a}$ & (0.91 to 0.97 ) \\
\hline \multirow[t]{2}{*}{$(\geq 9)$} & $3.36 \%$ & $100.00 \%$ & $\mathrm{n} / \mathrm{a}$ & 0.97 \\
\hline & (1.78 to 6.11$)$ & (99.73 to 100 ) & $\mathrm{n} / \mathrm{a}$ & (0.95 to 0.99 ) \\
\hline \multirow[t]{2}{*}{$(\geq 10)$} & $2.14 \%$ & $100.00 \%$ & $\mathrm{n} / \mathrm{a}$ & 0.98 \\
\hline & (0.94 to 4.55$)$ & (100 to 100$)$ & $\mathrm{n} / \mathrm{a}$ & (0.96 to 0.99 ) \\
\hline \multirow[t]{2}{*}{$(\geq 11)$} & $1.22 \%$ & $100.00 \%$ & $\mathrm{n} / \mathrm{a}$ & 0.99 \\
\hline & (0.39 to 3.32 ) & (100 to 100$)$ & $\mathrm{n} / \mathrm{a}$ & (0.98 to 100 ) \\
\hline \multirow[t]{2}{*}{$(\geq 12)$} & $0.92 \%$ & $100.00 \%$ & $\mathrm{n} / \mathrm{a}$ & 0.99 \\
\hline & (0.24 to 2.88 ) & (100 to 100$)$ & $\mathrm{n} / \mathrm{a}$ & (0.98 to 1.00 ) \\
\hline$(>12)$ & $0.00 \%$ & $100.00 \%$ & $\mathrm{n} / \mathrm{a}$ & 1.00 \\
\hline
\end{tabular}

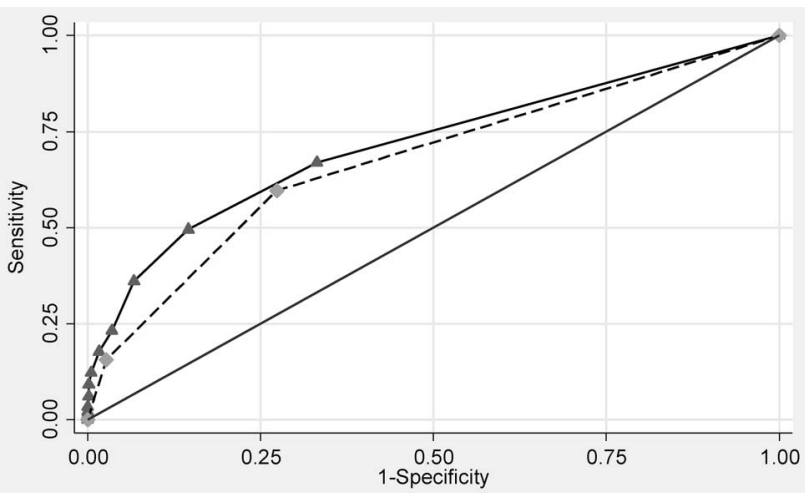

- pops ROC area: $0.7154 \quad-\sim-\cdot$ manchews ROC area: 0.6747 Reference

Figure 4 Receiver operating characteristics (ROC) curves for Manchester Children's Early Warning System (ManChEWS) and Pennine Acute Trust (PAT) Paediatric Observation Priority Score (PAT-POPS).

\section{DISCUSSION}

No universally validated children's EWS exists to predict likelihood of admission or discharge from the ED with illness or injury.

This research has demonstrated that, among children aged 0 16 years, PAT-POPS has slightly higher diagnostic accuracy for predicting the likelihood of admission than an existing tool often used in this population, ManChEWS, and that it can be used for patients with either trauma or illness.

The use of PAT-POPS in trauma patients as well as medical patients may sound counterintuitive: the decision to admit a patient with a trauma diagnosis from the ED can be based on factors and assessments that are quite different from those patients with a medical diagnosis (such as the need for operative intervention). Even though the original POPS was intended to be used on medical rather than trauma patients, the authors of this study believed that it would be interesting to evaluate how well PAT-POPS functioned on patients with a trauma diagnosis as well as a medical diagnosis. Some trauma patients would 
score highly in the categories of behaviour (if they were agitated or in pain) or nurse's judgement (a child with a severely deformed fractured limb).

A PAT-POPS score of 2 or more was associated with correct identification of $50 \%$ of children who were admitted from the ED, and a PAT-POPS score of less than 2 was associated with correct identification of $85 \%$ of children who were discharged from the ED. While this is a useful tool to aid decision-making on admissions in our population of patients, at a score of 2 or more, about half of children who were admitted would have been discharged, and $15 \%$ of those who were discharged home would have been admitted. Understanding which of these patients are more likely to be missed is a factor that should be addressed in future research. The results in this study compare favourably to previous studies. In a review of the performance of 10 Paediatric Early Warning Scores (PEWS) in predicting hospital admission of 17943 children aged 0-16 years attending an $\mathrm{ED}$, the area under the curve of the ROC curves (AUROCs) for the 10 PEWS ranged from $0.56(95 \% \mathrm{CI} 0.055$ to 0.58$)$ to 0.68 (0.66 to 0.69$){ }^{18}$

The NHS Institute PEWS is a valid tool with good diagnostic accuracy in recognising children at risk of serious and lifethreatening deterioration at triage in the ED, but further work is needed to determine whether other subjective measures have any value in paediatric early warning tools. ${ }^{19}$ In a study of children aged $0-16$ years a PEWS score of $\geq 2$ had a sensitivity of $37 \%$ and a specificity of $88 \%$. The authors concluded that PEWS is of limited value in predicting admission (in a triage setting) in a population of undifferentiated disease. However, a low PEWS score has a high specificity, that is, a patient scoring $<2$ is unlikely to need admission. ${ }^{20}$ PAT-POPS has a larger AUROC than any of the 10 PEWS tested in the study, and it contains more subjective criteria than PEWS, making it an ideal candidate for future work to resolve the concerns that were highlighted in the above two studies.

The mean PAT-POPS score was 0.9 on a scale of $0-18$ which may indicate that some of the items used to calculate the score may not be especially relevant, particularly at the lower end of the scale. Future work should investigate the weighted contributions of each of the components of PAT-POPS to the total score and whether there are some of the current components that could be either modified or removed without detrimental effect on the sensitivity and specificity reported in this study.

This initial study was undertaken as a service evaluation of a new tool and the intention is that, after this preliminary work, a multicentre study will be undertaken to investigate further. We recommend further research in two areas. First, refinement and validation of PAT-POPS should take place to ensure the various components in the score are combined together to make the most effective tool. Second, multicentre validation would be useful to determine if the effects found at our site are replicated elsewhere. In carrying out this further work there is a clear need to identify a gold standard outcome measure setting out clearly the criteria upon which the appropriateness, or otherwise, of an admission have been determined.

\section{KEY LEARNING POINTS FROM THIS STUDY}

- PAT-POPS has the potential to be an effective tool for use in deciding admission of children from the ED.

- Further research could refine the tool and enhance its predictive accuracy.

- There is a need to identify a robust gold standard outcome measure for hospital admission.
Twitter Follow Sarah Cotterill at @cotterillsarah1 and Andrew Rowland at @DrAndrewRowland

Acknowledgements The authors thank Christopher Hoare (Clinical Auditor) for substantial input into the data entry and initial data analysis as well as Dr Damian Roland, Consultant in Paediatric Emergency Medicine, for allowing them to modify POPS and for providing advice and guidance throughout this research project. The authors also thank four anonymous reviewers for their valuable comments.

Contributors SC wrote the first draft, undertook the statistical analysis, finalised the manuscript and revised the paper in response to reviewer comments. AGR conceived and led the research project, had substantial input into the writing, and revised the paper in response to reviewer comments. JK co-led the data collection, reviewed the draft manuscript and had substantial input into database design and data entry. HL co-led the data collection, reviewed the draft manuscript and had substantial input into database design and data entry. MK facilitated the literature search, contributed to data entry and reviewed the draft manuscript.

Funding Pennine Acute Hospitals NHS Trust Endowment funds covered some of the costs of this study.

\section{Competing interests None declared.}

Provenance and peer review Not commissioned; externally peer reviewed.

Open Access This is an Open Access article distributed in accordance with the Creative Commons Attribution Non Commercial (CC BY-NC 4.0) license, which permits others to distribute, remix, adapt, build upon this work non-commercially, and license their derivative works on different terms, provided the original work is properly cited and the use is non-commercial. See: http://creativecommons.org/ licenses/by-nc/4.0/

\section{REFERENCES}

1 Pearson GA, ed. Why children die: a pilot study 2006; England (South West, North East and West Midlands), Wales and Northern Ireland. London: CEMACH, 2008.

2 Chapman SM, Grocott MP, Franck LS. Systematic review of paediatric alert criteria for identifying hospitalised children at risk of critical deterioration. Intensive Care Med 2010;36:600-11.

3 Ferguson S, Stark M, Madar J. Paediatric early warning system (PEW) —a model for improved recognition and management of the critically ill. Arch Dis Child 2003;88:A30-2.

4 Joshi V, Barber R, Yates R. ManChEWS: Royal Manchester Children's Hospital early warning score. Crit Care 2011;15(Suppl 1):507.

5 Edwards ED, Powell CV, Mason BW, et al. Prospective cohort study to test the predictability of the Cardiff and Vale paediatric early warning system. Arch Dis Child 2009;94:602-6.

6 Akre $M$, Finkelstein $M$, Erickson $M$, et al. Sensitivity of the pediatric early warning score to identify patient deterioration. Pediatrics 2010;125:e763-9.

7 Parshuram CS, Duncan HP, Joffe AR, et al. Multicentre validation of the bedside paediatric early warning system score: a severity of illness score to detect evolving critical illness in hospitalised children. Crit Care 2011;15:R184.

8 Parshuram CS, Hutchison J, Middaugh L. Development and initial validation of the bedside paediatric early warning system score. Crit Care 2009;13:R135.

9 Duncan H, Hutchison J, Parshuram CS. The Pediatric Early Warning System score: a severity of illness score to predict urgent medical need in hospitalized children. J Crit Care 2006;21:271-8.

10 Roland D, Coats TJ. An early warning? Universal risk scoring in emergency medicine. Emerg Med J 2011;28:263.

11 ManChEWS website https://sites.google.com/site/emmedapps/home/manchews (accessed 2 Feb 2016).

12 Roland D, Davies F, Lewis G. Determining the effect of objective and subjective criteria on a risk assessment tool in a Children's Emergency Department. Emerg Med J 2011;28:A12-13.

13 Leicester POPS website http://www2.le.ac.uk/departments/cardiovascular-sciences/ research/cardiovascular-physiology-and-pathophysiology/emergency-medicine-group/ research/pemla/pops/pops-front-sheet (accessed 2 Feb 2016).

14 Roland D, Davies F, Coats T. The Paediatric Observation Priority Score (POPS): outcomes of 24000 patients. Arch Dis Child 2014;99:A24.

15 Deeks JJ, Altman DG. Diagnostic tests 4: likelihood ratios. BMJ 2004;329:168.

16 DeLong ER, DeLong DM, Clarke-Pearson DL. Comparing the areas under two or more correlated receiver operating characteristic curves: a nonparametric approach. Biometrics 1988;44:837-45.

17 Kelly J, Rowland AG, Cotterill S, et al. The Paediatric Observation Priority Score (PAT-POPS): a useful tool to predict likelihood of admission from the emergency department. Emerg Med J 2013;10:877-8.

18 Seiger N, Maconcochie I, Oostenbrink R, et al. Validity of different pediatric early warning scores in the emergency department. Pediatrics 2013;132;4:e841-50.

19 Sinitsky LL, Reece A. Effort of breathing is not an important parameter in a Paediatric Early Warning Scoring System. Arch Dis Child 2013;98:A6.

20 Bradman K, Maconochie I. Can paediatric early warning scores be used as a triage tool in paediatric accident and emergency. Eur J Emerg Med 2008; 15:359-60. 